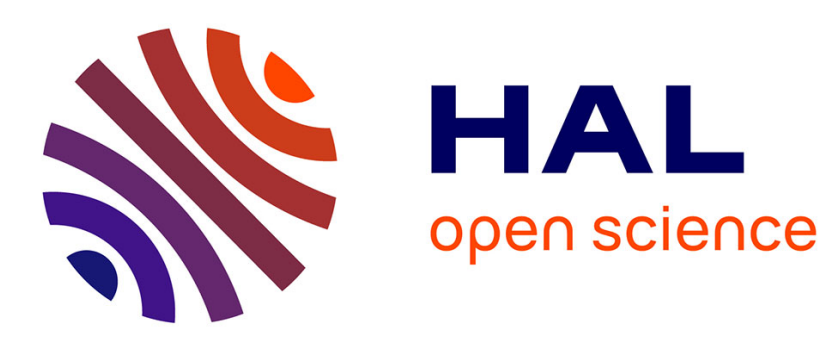

\title{
Frugal innovations and 3D printing: insights from the field
}

Josip Maric, Florence Rodhain, Yves Barlette

\section{To cite this version:}

Josip Maric, Florence Rodhain, Yves Barlette. Frugal innovations and 3D printing: insights from the field. Journal of innovation economics, 2016, Grassroots Innovation Processes, 3 (21), pp.57 - 76. 10.3917/jie.021.0057 . hal-01412871

\section{HAL Id: hal-01412871 \\ https://hal.science/hal-01412871}

Submitted on 8 Dec 2016

HAL is a multi-disciplinary open access archive for the deposit and dissemination of scientific research documents, whether they are published or not. The documents may come from teaching and research institutions in France or abroad, or from public or private research centers.
L'archive ouverte pluridisciplinaire HAL, est destinée au dépôt et à la diffusion de documents scientifiques de niveau recherche, publiés ou non, émanant des établissements d'enseignement et de recherche français ou étrangers, des laboratoires publics ou privés. 


\title{
FRUGAL INNOVATIONS AND 3D PRINTING: INSIGHTS FROM THE FIELD'
}

\author{
Josip MARIC \\ Montpellier Research in Management (MRM) \\ University of Montpellier, France \\ josip.maric@etu.umontpellier.fr \\ Florence RODHAIN \\ Montpellier Research in Management (MRM) \\ University of Montpellier, France \\ florence.rodhain@univ-montp2.fr \\ Yves BARLETTE \\ Montpellier Research in Management (MRM) \\ Montpellier Business School, France \\ y.barlette@montpellier-bs.com
}

Developing countries are experiencing ongoing and rapid population growth. According to current estimates, approximately four billion people live in these countries, which can be described as low-income markets in which the majority of the population survives on minimum wage (Prahalad, Mashelkar, 2010). Govindarajan and Trimble (2013) refer to this phenomenon as "mega markets with micro customers". Many scholars have argued that consumers from emerging markets form the Base-of-the-Pyramid (BoP) (Prahalad, 2004).

The slum settlements of Mumbai, for instance, contribute up to six percent of India's national Gross Domestic Product (GDP) and have an employment rate of up to sixty percent (Brand, 2006). This makes developing countries a focal point for companies wanting to tap into the pool of new markets and the needs of BoP consumers (London, Hart, 2010). However, questions remain as to how to innovate to serve the needs of the BoP.

The solution is to innovate and work differently (Zeschky et al., 2014). Frugal innovation, a scarcity-induced or minimalist approach to innovation,

1. Acknowledgments: This article received support from the French government through National Research Agency, under "Investissements d'avenir" program, reference number ANR10-LABX-1 1-01. 
is becoming more popular in both emerging and developed economies because of its lower costs and lower-leveled structures (Jha, Krishnan, 2013). Frugal innovations are seen as low-priced, yet valuable products that can drive profits through volume and meet the needs of resource-constrained customers (Seghal et al., 2011; Zeschky et al., 2011).

Although the term "frugal innovation" does appear in the press, both the term and its associated phenomena in the developing world are not adequately covered by scholars or scientific publications (Brem, Ivens, 2013). In this article, we focus on introducing frugal innovation. Frugal innovation offers the ability to generate considerably more business and social value while significantly reducing the use of scarce resources (Radjou, Prabhu, 2013). It is about a mindset of doing more with less. Frugal innovation is seen as a game changer in the corporate world's search for affordable, sustainable and high-quality offerings. The idea behind frugal innovation is to design for the BoP taking into account local contexts, socioeconomic conditions and consumer needs (Lecomte et al., 2013).

We conceptualize the intersection of society, emerging technology and the societal impact of innovation to identify, understand and position frugal innovations. We adopt a holistic view of frugal innovation that has the potential to redefine business models, reconfigure value chains and redesign products to use resources in different ways and create more inclusive markets (Bhatti, 2012).

Moreover, we focus our paper on state-of-the-art 3D printing as an example of frugal innovation. Additive manufacturing, which is also known as three-dimensional (3D) printing, constitutes a novel manufacturing process that builds layers to create a three-dimensional solid object from a digital model (Birtchnell, Urry, 2013; Berman, 2012). 3D printing technology has been identified as one aspect of the digital revolution that has the potential to revolutionize the industrial world. 3D printing is considered a game changer for the manufacturing industry that could completely reconfigure existing business models. It has even been proposed that 3D printing will bring both modern and developing societies to the brink of a new Industrial Revolution (The Economist, 2012).

Nevertheless, society has barely begun to measure the effects of this innovation (Gebler et al., 2014; Le Bourhis et al., 2014). Our intention is both to examine 3D printing as a frugal innovation and to identify the possibilities of $3 \mathrm{D}$ printing from a frugal perspective. By examining the growing 3D printing sector in conjunction with a frugal innovation perspective, we discover the dual nature of 3D printing. By studying this dual nature of 3D printing, as a low-cost frugal 3D printers in developing markets and 3D printing in 
enabling the development of frugal innovations in other sectors, our paper questions some features of frugal innovation and offers new insights into how democratizing technology enables development for the BoP population.

This paper is organized as follows: section 1 presents the theoretical background of the paper, providing insights on frugal innovation, additive manufacturing, the maker culture and value creation. Section 2 discusses the dual nature of 3D printing as a novel technology and uses two example stories to elaborate the features of frugal innovation and open a discussion on socio-economic opportunities lying for the BoP. Last section, section 3, analyzes the findings on the subject and offers our concluding thoughts.

\section{THEORETICAL BACKGROUND}

\section{Frugal innovation: origin and mindset}

Either because of certain standpoints (religious, philosophical or other) or merely from pure necessity, frugality is largely practiced by "consumers" in developing markets. It is in those markets that a form of innovation theory, referred to as frugal innovation, is emerging whose impact could potentially diffuse to developed markets.

Etymologically, the word "frugal" derives from the mid-sixteenth-century Latin word frugalis. Today, the Oxford English Dictionary defines frugality as being sparing or economical with money or food (Soni, Krishnan, 2014). Lastovicka et al. (1999) argue that frugality has been used to describe individuals or groups who live by a set of principles that contradict the dominant materialistic consumer culture. Frugality has been documented in the ancient world and is linked with deficient economic resources. This condition is quite similar to that of modern developing countries and emerging markets, where the majority of the world's poor live.

Frugal innovation, as mentioned earlier, is rooted in developing countries, in the mindsets of Jugaad in Hindi or Shanzai in Mandarin (Radjou et al., 2012; Brem, Wolfram, 2014). The tradition of Jugaad - making do with what is available (Rangaswamy, Densmore, 2013) - is said to stem from a combination of India's cumbersome and inefficient state bureaucracy and long history of rural poverty.

Brem and Ivens (2013) explain that frugal innovation is a successor of Jugaad, meaning an innovative fix or an improvised solution born from ingenuity and cleverness (as do Radjou et al., 2012). Jugaad captures an improvisational style of innovation driven by scarce resources and attention to 
the immediate needs of customers (Bhatti, 2012). Jugaad, in other words, focuses on the problem that requires an immediate solution. This results in developing simple products with high benefits at low cost that are designed for people at the BoP. It is basically a new way of thinking constructively, in a more frugal manner, being flexible and adapt quickly to unforeseen situations and circumstances.

\section{Defining frugal innovation}

Frugal innovation (sometimes called Gandhian innovation) is most closely associated with India. The term is used to describe the process by which engineers and designers strip out 'luxury' features to lower costs (Radjou et al., 2012; Leadbeater, 2014). Although this phenomenon is not new, the literature exploring it remains in its early stages.

The term describes innovations specifically developed for resource-based customers in emerging markets (Zeschky et al., 2014; Prahalad, Mashelkar, 2010). Frugal innovation, therefore, fundamentally refers to resource scarcity in using limited resources to meet the needs of low-income customers (Sharma, Iyer, 2012). Value and affordability are the key drivers of such innovations (Prahalad, Mashelkar, 2010). In such a state or reality, frugal innovation contradicts common logic which accepts the theory that innovation occurs in existing resources and supporting institutions, with highincome users being the first target group (Bhatti, 2012). Frugal innovation's goal is to maximize value for low-income customers and minimize inessential costs (Seghal et al., 2011).

The economic relevance of frugal innovation is the creation of low-cost market products that are affordable for all social groups, including marginalized ones (McGee, Sammut-Bonnici, 2014). Frugal innovation products are, thus, less complex, easier to handle and considerably cheaper in terms of production costs.

With the exception of Gupta (2011) who elaborated frugal innovation in a sense of a new management philosophy, the majority of the aforementioned authors focus solely on the product perspective on frugal innovation. Gupta and Wang (2009) offered a broader definition of frugal innovation as the development of simple and ecological products, services, processes and business models requiring low input of resources, low cost and little environmental intervention. Bhattacharyay (2012) explains that frugal innovation as a management philosophy refers to the extensive approach of adapting product management, production and development to achieve a sufficient level of taxonomy, but avoiding high research and development $(R \& D)$ investments. Thus, frugal innovation combines low-cost solutions, 
low-cost manufacturing and low-cost materials with design that focuses on basic functionality and a minimal set of features (Simula et al., 2015).

For the purpose of this paper, we base our work on the definition of Zeschky et al. (2014) and other scholars who define frugal innovation as a product or service developed for very specific applications in resourceconstrained environments, generating an entirely new value proposition.

What frugal innovation requires further is disassociation from similar terminology in the existing literature. Terms such as cost innovation (Williamson, 2010), good-enough innovations (Gadiesh et al., 2007), frugal innovation (Radjou et al, 2012; Zeschky et al., 2011), resource-constrained innovation (Ray, Ray, 2010) and reverse innovation (Immelt et al., 2009; Govindarajan, 2012) are misused quite often by the researchers and practitioners, obscuring the differences between them (Zeschky et al., 2014).

\section{Additive manufacturing}

3D printing aims to produce three-dimensional objects from a digital model; layers are built one on top of another as the printer releases material from a container or a cartridge. Every layer is a digital slice generated through computer-aided design (CAD) (Birtchnell, 2013). It refers to a procedure that turns digital files into solid objects. These solid objects are first designed using a computer and CAD software and are then fabricated using a 3D printer. Digital model is sliced into many cross-sectional layers that a 3D printer can print, placing each one on top of another.

Once the digital file is ready, fabrication is very simple, customizable and relatively quick. With slight modifications on the initial digital file, a new object is manufactured without cost and without effort. This means that based on the same digital file, many customers with different profiles and different needs may have a customized product that fulfils their needs in a more efficient way. This practically means better and improved communication between designers and consumers (Mavri, 2015).

Materials used in the process include resin, ABS, nylon, carbon, titanium or steel (Berman, 2012). The number of promising applications of 3D printing has expanded dramatically over the last few decades in industries such as aerospace, architecture, automotive goods (Metal Powder Report, 2014a), defense, education (Reichental, 2014), energy (Bradley, 2014), entertainment (Harouni, 2014) and healthcare (Atala, 2014; Rankin et al., 2014; Moskvitch, 2011; Petrovic et al., 2011). What remains inevitable is that 3D printing, as a disruptive technology, follows the same adoption pattern as other disruptive technologies, like PC or Internet for instance (Eisenberg, 2013). 
Rayna and Striukova (2016) discussed 3D printing adoption - originally developed in 1980s as rapid prototyping technique - 3D printing technology progressively led to a wider adoption led by lowered price. This manifested in second stage of 3D printing adoption, in the 1990s, as rapid tooling. This had a large use in developing customized tools and 3D-printed molds. Third phase of adoption, originating in late 2000s, refers to as Direct Digital Manufacturing (DDM) or direct manufacturing. This enabled fabrication of final products due to the low cost of 3D printing. The fourth and final stage of adoption, home fabrication, has just started and it consists of direct communication between the designers and the consumers who manufacture objects themselves, using 3D printing equipment at home.

Last two stages of adoption constitute the 3D printing biggest disruptive potential on transforming the steps of the production chain ${ }^{2}$. However, it is argued that a limited and slow adoption is to be expected as prices of $3 \mathrm{D}$ printers are still relatively high and the technology is yet immature. Instead of mass home fabrication, we are witnessing to an intermediary stage between direct manufacturing and home fabrication that places fabrication at a local print-shop or community-operated organization. This subject is presented further in the text.

Figure 1 - Schema of 3D printing process (Mavri, 2015)

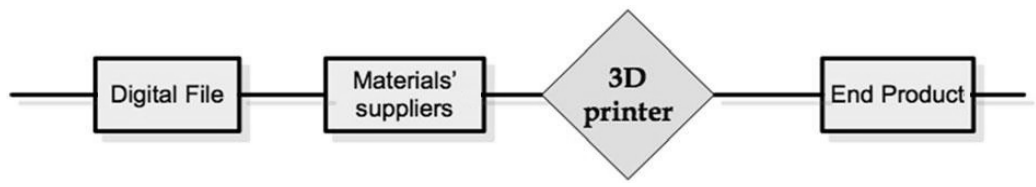

\section{Indicators of growth and future trends}

Although the technology for $3 \mathrm{D}$ printing is more than 30 years old, it was not until the last decade that barriers to $3 \mathrm{D}$ printing came down, making it more accessible. What makes this technology so interesting is that the adoption of 3D printing technology allows non-experts to access expert capabilities. There is a growing consensus that $3 \mathrm{D}$ printing technologies will be one of the next major technological revolutions, making paradigm shift from mere consumers to makers (Rayna, Striukova, 2016).

Economic estimates of relevant market reports are ranging between 8 and 20 billion of US dollars by the year 2020 (Metal Powder Report, 2014b; Wohler's Report, 2014; McKinsey and Co., 2014). Moreover, approximately

2. Production chain is defined as "the procedure of transforming raw materials into goods" (Mavri, 2015). 
30 innovative companies showcased their latest advancements in 3D printing technology at the world's largest Consumer Electronics Show (2015) in Las Vegas (CES Press Release, 2015). Trend in development is shifting towards more compact printer units, which would be more suitable for consumers, most likely to print mixed and complex materials (as the case of the MIT prototype) (Numerama, 2015).

Growing interest, except economic parameters, can be observed from D'Aveni's (2015) report that discussed the industrial adoption of 3D printers compared to traditional manufacturing. Report showed that additive manufacturing patents related to materials, software and equipment issued worldwide grew from eighty in 2005 to approximately six hundred in 2013. This growth is close to eight hundred percent, showing great promise for the future of the additive manufacturing sector.

\section{The maker culture movement}

The raise of commons-based peer production, i.e. individuals collaborating in producing cultural content, knowledge, and other information and indeed physical goods, is commonly attributed to 'digital revolutions', the broad availability of new information technologies (Benkler, 2006).

Commons-based peer production, although most widely practiced in the area of software development, moved beyond pure software and spread into other domains, from culture and education to knowledge discovery and sharing (Troxler, 2010). That sparked quite a few open source hardware and software initiatives that aim to produce tangible and intangible goods through a peer-production approach.

There has been a rise in the number of organizations typically known as Hackerspaces and Makerspaces which have the potential to serve as a non-traditional route to skill learning and personal development in, particularly, technology and computing (Lewis, 2015). Hackerspace can be defined as community-operated physical places, where people can meet and work on their projects (Hackerspace, 2010). Makerspace, on the other hand and in a simplified way, can be understood as a contemporary culture of Do-ItYourself (DIY) concerning physical objects.

Both terminologies can be linked to contemporary open-source hardware and software movements that are closely intertwined. They tend to be non-profit organizations that operate primarily on a membership basis. In exchange for a membership fee, members receive access to space, tools, technologies and expertise to develop skills in a wide range of areas relevant to manufacturing, digital arts and computing. Our approach is not to study 
the initiatives in details but, based on their ideological construct of knowledge exchange as a primary resource, justify how these movements lead to development of frugal solutions within 3D printing technology.

\section{Emergence of fab labs}

When speaking solely about manufactured physical goods, Gershenfeld (2005) argued emergence of digital personal fabrication, or fabbing. He presented fabbing as commons-based peer-production of physical goods. A fab lab (shorter for digital fabrication or fabbing laboratory) is a small-scale workshop with an array of computer-controlled tools (for instance lasers, 3D printers and mills) that cover several different length scales and a variety of materials, thus democratizing manufacturing technologies that were previously available only for expensive mass production (Gershenfeld, 2012).

Fab labs are another global initiative based on the principles of maker culture with a growing number of locations around the world. They emerged from an MIT course entitled How To Make (almost) Anything (Gershenfeld, 2005) and ever since spread around the globe. It is interesting to mention that the community is catching on the momentum in Europe in recent years, while fab labs can be found also in great number of African and Asian countries ${ }^{3}$.

Important feature of the fab labs (along with similar global initiatives of self-doers) lies in enabling open and collaborative projects. Moreover, fab labs provide avenues for affordable and non-expensive R\&D. There are some collaborative projects within the community, and a growing number of initiatives to exchange designs and experience between the labs. As such, entire communities benefit from them, rather than just individuals (Menichinelli, 2011). This, on the other hand, enables easier transfer of technology between developed and developing world, as described in following section, particularly sub-sections.

\section{Value Creation}

Co-creation, as defined by Prahalad and Ramaswamy (2004), is a management initiative, or a form of economic strategy, that brings different parties together (for instance, a company and a group of customers), in order to jointly produce a mutually valued outcome. As they argue, in the context of

3. Listing of all official fab labs is maintained by community using site www.fablabs.io. Most recent figures from September 2015 number $107 \mathrm{fab}$ labs in the US and Canada, and 270 in Europe (565 in the world in total). 
companies and acquiring new sources of competitive advantage, co-creation is a high-quality interaction between an individual customer and a company to co-create unique experiences and value. In other words, the meaning of value and the process itself of value creation is shifting from a product and a company-centric view to personalized consumer experiences.

According to Redlich et al. (2014), the value creation processes are broadly dependent on interaction, collaboration, and self-organization of globally distributed actors to cope with emerging complexities. In the traditional system, companies decide the products and services they will produce and they decide what the value to the customer is. Consumers have little or no role in the value creation in these system foundations. Co-creation disturbs this logic by involving consumers, which effectively leads to new ways of value creation and value extraction.

Taken out of the context of companies and competitive advantage, and laid over the maker culture initiatives and tools available in the communityoperated organizations, co-creation enables development of solutions which consumers (or end-users, to state it differently) desire. It is about creating platforms that connect consumers from far reaching parts of the globe, by permeating society, shifting identity and meaning from consumption to creation and blurring the boundaries between consumers and creators. This is, argued by scholars and practitioners, what likely the future of consuming is going to be.

3D printing, placed in such a value creation system of makerspaces/hackerspaces, driven by open source hardware and software community-operated organization that allow far greater access to general public, leads to new ways of doing innovation and developing solutions that serve the needs of BoP. In the context of frugal innovation, it is about frugal innovation outcome: low-cost solutions that meet the needs of resource-constrained population (Zeschky et al., 2014). This is on what we base our approach and discuss the related issues further in the text.

\section{RESEARCH ISSUES}

The next major industry to be changed by the digital revolution is manufacturing. We are currently witnessing important advances in the capabilities of $3 \mathrm{D}$ printing and the types of materials that it can use. This enables applications beyond prototyping and industrial use and precipitates changes in the entire value chain surrounding how products are designed, planned, manufactured and distributed (Mavri, 2015). 
Cases of disruptive use of 3D printing are found mostly in the healthcare, energy-production and transportation sectors; many solutions are also coming from emerging markets in India, China and African countries. These markets present us innovative business opportunities related to frugal innovations and this matter has been under much greater scholar interest (Agarwal, Brem, 2012).

In the next two sub-sections, we present how interplay between 3D printing technologies, enabled through access of community-operated organizations like fab lab in our first case, contributes to value creation when technology reaches developing countries. We present the dual nature of 3D printing: first, as a frugal innovation in itself; and second, as a technology that fosters the development of frugal solutions in other sectors, healthcare in our case.

\section{The emergence of frugal low-cost 3D printer[s]}

Frugal innovation can create opportunities for the poor and improve their well-being in four important areas: income generation and security, education, infrastructure and distribution. Thus, bottom-up initiatives are promising ways to combat poverty and enable sustainable development.

The transformative power of 3D printing, as discussed above, allows latecomers to the developing world to catch the wave of this technological innovation in its early phase. Environments in which frugal innovations emerge are characterized by low and irregular incomes, limited education, inadequate infrastructure and fragmented distribution (Kahle et al., 2013). This is where democratized technology steps in. For instance, free 3D printers are easily accessible using open-source models. RepRap is a free desktop 3D printer capable of printing plastic objects and self-replicating in the form of a kit. RepRap.org is a community project that began in 2004 as a sort of outcome of open source and maker culture movement. This means that the kit can be assembled by anyone who can provide the time and raw materials.

What is interesting about RepRap.org's role in fostering frugal innovations? RepRap.org's overall project outcome is the first low-cost and most widely used 3D printer among the global members of the maker community (RepRap Community, 2015). Assuming simple technology transfer from the developed countries of the North to the developing countries of the South is insufficient (Rangan et al., 2007), the RepRap.Org project offers one revolutionary mean of technology transfer that questions postulates of modern society. 
The project's activities translate into open technology for developing countries. For instance, an example of assembled 3D printer from electronic waste collected in dumps around the Togolese capital of Lomé proves that Africa stands on the tipping point of the next digital revolution. Afate Gnikou, Togolese entrepreneur and a member of local fab lab community, developed 3D printer which integrates leftover parts gathered from old computers, printers, and scanners found in local dumps (Fast Company, 2015).

This is a classic example of "Kabaad se jugaad," a Hindi slang expression referring to the conversion of waste (kabaad) into something useful and beautiful. As a result, new businesses develop from creative ideas, allowing inventive inhabitants of developing countries, constrained by poverty and a lack of resources, to become entrepreneurs (Brem, Wolfram, 2014).

Afate Gnikou was able to leap to the frontiers of technological innovation primarily because of the large amounts of scientific and technical knowledge (about 3D printing) that are freely available today. A huge portion of the BoP population is constrained by the lack of skills and lack of knowledge of the market or of competitive prices, which turns into obstacles to the development of new frugal products. This is where democratized technology helps bridge the gap, as in the case of 3D printing.

In the case of Gnikou's machine itself, few new parts had to be purchased as the vast majority of the $3 \mathrm{D}$ printer was built using repurposed local materials. This demonstrates a novel mindset in combating issues related to WEEE (Waste of Electric and Electronic Equipment) shipped to the developing world.

Moreover, by giving means of production and democratizing technology transfer to developing world, it allows integration of even low-income consumers into overall global market. Moreover, it allows development of new products and services and allows latecomers to grasp the potential of new emerging technologies. In the case of 3D printing - unlike other emerging technologies - the African continent is not behind in adopting it. Prahalad (2012) argued that providing access to and distribution of products and services to consumers, even in isolated areas, increases diversity and competition, lowers prices and increases incomes.

Described printer model can be extracted and re-created in any environment using existing equipment (Fast Company, 2015). This development could represent a major breakthrough in Western societies and their standpoints related to WEEE, including its negative impacts in the poor or developing countries of Africa and Asia. 
Moreover, this story touches upon the entrepreneurial spirit of 3D printing and frugal innovation because its protagonist is referred to as a "grassroots frugal innovator." Such innovators are best described as individuals or groups of people who are embedded in strong social ties and having limited access to non-redundant information and resources and who attempt to solve personal and societal problems both without relying on institutional support and by adopting locally available ingenuity (Gupta, 2006; Soni, Krishnan, 2014). Such a bricolage approach, or Jugaad mindset, attempts to achieve a desired objective with the resources available at hand (Radjou et al., 2012; Krishnan, 2010). The solutions these innovators develop address domestic markets, usually of the BoP.

Finally, this story proves that we will be witnessing an increase in similar examples fostered by the maker culture community as a result of the expiration of critical patents. Eventually, this will translate into the explosive emergence of projects with far-reaching technological development implications for the BoP in fields such as consumer goods, healthcare, industry, agriculture, fashion, culture, art and construction. Providing more opportunities, as in the case of 3D printing that reached frugal mindset, will lead to new forms of innovation. Frugal innovation thus enables inclusive growth, reduces inequality and contributes to participation and empowerment.

\section{D printing-enabled frugal innovations}

As discussed above, there have been major breakthroughs in the use of 3D printing for medical purposes. 3D printing has already led to amazing advances in medicine: it is capable of saving lives, lowering health care costs and improving the quality of human life (Rankin et al., 2014).

Further investments in 3D printing for medical purposes are expected. For instance, in 2014 the Japanese government announced that it will invest the massive sum of approximately $\$ 21$ million into the development of transplantable human organ printing over the next five years. Russian scientists have announced that they will be able to 3D print human kidneys by 2018. The Yale School of Medicine aims to pioneer 3D bio-printed surgical tissues (Moskvitch, 2011).

In addition to these upcoming advancements-bordering on science fiction-we see the true potential of 3D printers in the context of frugal innovation for developing countries. Because 3D printing offers mass customization and lower production costs compared to traditional manufacturing methods, its successful use in producing prosthetics can support radical changes and make a significant difference in the lives of people from developing and poor 
countries. The poor are often are confronted by higher prices and lack of choice in basic goods, preventing them from fully participating in markets (Kahle et al., 2013).

$3 \mathrm{D}$ printing offers local production options for some sorely needed items in developing countries, particularly prosthetics. Business opportunities originating in these low-income emerging markets are sometimes challenging presupposed business models. Thus, there is a need not only for innovative products but also for innovative business models that are especially designed to serve BoP markets (Simula et al., 2015). This is an important factor in the sense of frugality because it shows that frugal innovation can comprise not only products and services but also integrated business models.

Consider the success story of 3D Life Prints, a venture based on the idea set in meeting the needs of low-income customers of BoP, whose mission is to work with local institutions and international non-governmental organizations (NGOs) to give local amputees new chances in life (3D printing Industry, 2015). The 3D Life Print team uses basic 3D scanners to reproduce the exact shape of amputees' limbs and develop new prosthetic models. Although the project is in its infancy, its first set of patients received lowcost hand prostheses and prosthetic leg covers for their lower-limb prostheses. In terms of affordability, this project resulted in affordable leg covers and prosthetic hands designed and 3D printed at costs of less than $\$ 50$ each. In comparison, prostheses produced using traditional manufacturing methods can cost up to several thousands of US dollars.

The long-term goal of this venture is to bring affordable 3D printing technologies to amputees and healthcare facilities in all of the world's poor and developing nations. The basic idea in this story is that technology can bridge the development gap in providing low-income solution serving as a new business opportunity (Simula et al., 2015). Digital manufacturing makes it possible to skip over traditional mass manufacturing in particularly isolated parts of the world. Moreover, this story confirms how 3D printing can provide solutions and supply small markets while producing customized products.

Moreover, how 3D printing can be used in development of prosthetic implants for BoP is seen in Project Daniel. Not Impossible Labs, a nonprofit that creates technological solutions for real-world problems, set up a 3D printing lab that creates prosthetic limbs for children affected by the war in Sudan. With the estimated 50,000 amputees as a result of the endless conflict in that region (3D printing Industry, 2014) 3D printing was used here to develop prosthetic implants fabricated 3D scanners 3D printers. Based on open-source software, discussion forums and crowd-sourced answers this 
example demonstrates what immense potential 3D printing holds for the innovation where life hacks are sorely needed.

The process developed is simple in its concept: the amputated limb must be scanned, and with 3D scanners, doctors can create digital models of wounds and decide the best method of recovery for the patient. The scan then must be converted into a 3D model; 3D models of prosthetic implants are then fabricated based on 3D scanners and using 3D printers (Mavri, 2015). Thanks to modern technologies, this entire process can take less than a day, even using low-level 3D printers and scanners. Whereas the quality of a 3D printed model varies in quality and depends on real-world conditions, the overall goal is not to replace existing methods of producing prosthetic limbs, but to meet the need that is currently unmet by traditional manufacturing methods. This is a true manifestation of the concept of frugal innovation...

When discussing this case in terms of adoption of frugality, it is clear that minimal use of resources during the design phase and in realizing the product did not effect on its final efficient functioning. The approach undertaken here starts with deep insights into local customer (or end-user) needs and combining resources in a new and creative way. In this way, a low-cost solution can offer high value for low-income customers. Innovators at the BoP are driven by the requirements of reaching product awareness, access, affordability and availability (Prahalad, 2012; Kahle et al., 2013). By economizing the use of resources and aiming for simple products and services, frugal innovations have much to offer in terms of sustainable development.

With this example of 3D printing technology used for the development of prosthetic implants, our intention was to show the business opportunity inherent in the growth of the additive manufacturing sector. Moreover, there is much to be done in terms of discussing and comparing 3D printing with similar technologies that may develop the same solutions. That issue, however, was not part of our paper. We have focused on the presentation of $3 \mathrm{D}$ printing as a technology in terms of democratized environment, where it leads to development of frugal solutions - as in the case of first venture, a business model or as a low-cost frugal product.

\section{CONCLUDING REMARKS}

It has been predicted that 4.8 billion people will belong to the global middle class by 2030 (Roland Berger Strategy Consultants, 2015). This will result in higher incomes, growing demand, millions of consumer desires, and the 
need for millions of machines to manufacture entirely new products. This presents a challenge to target these new market potential but at the same time raises question on 'how to do so?'

Additive manufacturing, also referred to as $3 \mathrm{D}$ printing, is a part of a bigger trend that is reshaping the industrial sector into something very different from what has typically characterized manufacturing. This technology turns traditional manufacturing upside down, offering light, decentralized, almost "guerilla" options for manufacturing. As we discussed in our paper, various $3 \mathrm{D}$ printing projects designed to address the needs of BoP customers are a symbol of something truly inspiring.

We have elaborated that 3D printing holds the potential to enable new innovation theory application within the production chain. Frugal innovation has been presented in the form of products development (in the case of low-cost frugal 3D printer) or in the form of services development and business model innovation (as in the case of 3D printing-enabled frugal solutions in prosthesis development). Dual nature of 3D printing, as we have referred to it, questions management postulates and targets radically new values, by adopting a clean-slate approach and fostering an attitude of frugality within frugal innovation theory (Prahalad, Mashelkar, 2010; George et al., 2012; Radjou et al., 2012; Soni, Krishnan, 2014).

We have discussed that by enabling consumers to have far greater impact on co-creation through frugal innovations in $3 \mathrm{D}$ printing has the potential to improve lives and to integrate those who were previously excluded from the formal economy. By integrating the poor into the formal economy it improves their standard of living, positively affects socioeconomic development through democratizing effects and has a positive and sustainable impact on economic empowerment, social development and democratization (Mair et al., 2012).

We have tried to use example stories that bolster our aforementioned theory. Moreover, like mobile phones and similar emerging technologies, $3 \mathrm{D}$ printing is presented here as a crucial technology that could be the game changer in enabling the developing world to leap into a new age of industrial production. Many significant technologies were widely adopted at some point in their development as innovations, becoming reality and changing who and what we are. Thus, scholars are encouraged to engage in this field of research. Opening a discussion on questions related to 3D printing and frugal innovations, identifying success stories and good practices will spur not only the next wave of knowledge but also more responsible and sustainable development of the new products and services made possible by this technology. 
Certain limitations are presented in the form of scoped review on the success stories used in our paper. Significant collaborative projects exist that also confront the traditional value creation chain. Moreover, we would like to highlight that our intention with this paper was not to go into details of describing $3 \mathrm{D}$ printing as manufacturing method but to present it as a part of a larger value chain, incorporating maker culture movement and frugal innovation theory, which leads to development of frugal solutions. Also, we would like to highlight that this paper requires further analysis of available methods for developing low-cost prosthetic implants. Thorough comparison of $3 \mathrm{D}$ printing and such similar methods, in the context of frugal innovation presents future perspectives of our paper.

\section{References}

3D PRINTING INDUSTRY (2014), 3D Printed Prosthetics for Sudanese Amputees: Initiated by Project Daniel, Accessed online in 2016. URL: http://3dprintingindustry. com/2014/01/16/3d-printed-prosthetics-sudanese-amputees-initiated-project-daniel/

3D PRINTING INDUSTRY (2015), 3D printing Prosthetics in the Developing World: An Interview with 3D Life Prints, Accessed online in 2016. URL: http://3dprintingindustry. com/2015/03/24/mobility-takes-whole-different-meaning-3d-life-prints-africa-asia/

AGARWAL, N., BREM, A. (2012), Frugal and Reverse Innovation: Literature Overview and Case Study Insights from a German MNC in India and China, Engineering, Technology and Innovation (ICE), 18th International ICE Conference, IEEE, 1-11.

ATALA, A. (2014), Printing a Human Kidney, TED talks, Longbeach (CA), USA, Accessed online in 2016. URL: www.ted.com

BENKLER, Y. (2006), The Wealth of Networks. How Social Production Transforms Markets and Freedom, New Haven and London, Yale University Press.

BERMAN, B. (2012), 3-D Printing: The New Industrial Revolution, Business Horizons, 55, 155-162.

BHATTACHARYAY, B. (2012), Seamless Sustainable Transport Connectivity in Asia and the Pacific: Prospects and Challenges, International Economics $\&$ Economic Policy, 9(2), $147-189$

BHATTI, Y. (2012), What is Frugal, What is Innovation? Towards a Theory of Frugal Innovation, University of Oxford, Said Business School, Oxford Centre for Entrepreneurship and Innovation, Working paper, Accessed online in 2016. URL. http://papers.ssrn.com/ sol3/papers.cfm?abstract_id $=2005910$

BIRTCHNELL, T., URRY, J. (2013), 3D, SF and the Future, Futures, 50, 25-34

BRADLEY, D. (2014), Printing a Tiny 3D Battery, Materials Today, 16(7-8), 256.

BRAND, S. (2006), What Squatter Cities Can Teach Us?, TED talks, Monterey (CA), USA, Accessed online in 2016. URL:https://www.ted.com/talks/stewart_brand_on_squatter_cities\#t-11741 
BREM, A., IVENS, B.S. (2013), Do Frugal and Reverse Innovation Foster Sustainability? Introduction of a Conceptual Framework, Journal of Technology Management for Growing Economy, 4(2), 31-50.

BREM, A., WOLFRAM, P. (2014), Research and Development from the Bottom Up: Introduction of Terminologies for New Product Development in Emerging Markets, Journal of Innovation and Entrepreneurship, 3(9), 1-22.

CES PRESS RELEASE (2015), 3D Printing Marketplace Doubles in Size at 2015 International CES, Accessed online in 2016. URL: https://www.cesweb.org/News/PressReleases/CES-Press-Release.aspx?NodeID=eba42759-2d4c-4af7-bc9a-d74f4d3cOfec

D'AVENI, R. (2015), The 3-D Printing Revolution, Harvard Business Review, Accessed online in 2016. URL: https://hbr.org/2015/05/the-3-d-printing-revolution

EISENBERG, M. (2013), 3D Printing for Children: What to Print Next?, International Journal of Child-Computer Interaction, 1, 7-13.

FAST COMPANY (2015), This African Inventor created a $\$ 100$ 3-D Printer from E-Waste, Accessed online in 2016. URL: http://www.fastcompany.com/3019880/this-african-inventor-created-a-100-3-d-printer-from-e-waste

GADIESH, O., LEUNG, P., VESTRING, T. (2007), The Battle for China's Good-Enough Market, Harvard Business Review, 85(9), 81-89.

GEBlER, M., SCHOOT UITERKAMP, A. J. M., VISSE, C. (2014), A Global Sustainability Perspective on 3D Printing Technologies, Energy Policy, 74, 158-167.

GEORGE, G., MCGAHAN, A. M., PRAHBU, J. (2012), Innovation for Inclusive Growth: Towards a Theoretical Framework and a Research Agenda, Journal of Management Studies. 49(4), 661-683.

GERSHENFELD, N. (2005), FAB: The Coming Revolution on Your Desktop, from Personal Computers to Personal Fabrication, Cambridge, Basic Books.

GERSHENFELD, N. (2012), How to Make Almost Anything, Accessed online in 2016. URL: http://www.foreignaffairs.com/articles/138154/neil-gershenfeld/how-to-make-almostanything

GOVINDARAJAN, V. (2012), A Reverse Innovation Playbook, Harvard Business Review, 90(4), 120-124.

GOVINDARAJAN, V., TRIMBLE, C. (2013), Reverse Innovation: Create far from Home, Win Everywhere, Harvard Business Press.

GUPTA, A. K. (2006), From Sink to Source: The Honey Bee Network Documents Indigenous Knowledge and Innovations in India, Innovations, 1(3), 49-66.

GUPTA, A. K., WANG, H. (2009), Getting China and India Right, New York, Jossey-Bass/ Wiley.

GUPTA, V. P. (2011), Frugal Innovation: The New Masters of Management, 'Jugaad' to Frugal Innovation, Accessed online in 2016. URL: http://www.indianmba.com/Faculty_ Column/FC1283/fc1283.html

HACKERSPACES (2010), Hackerspace Wiki, Accessed online in January 2016. URL: http://hackerspaces.org/wiki/

HAROUNI, L. (2014), A Primer of 3D Printing, TED talks, London, UK, Accessed online in 2016. URL: http://www.ted.com/talks/lisa_harouni_a_primer_on_3d_printing. 
IMMELT, J., GOVINDARAJAN, V., TRIMBLE, C. (2009), How GE is Disrupting Itself, Harvard Business Review, 87(10), 56-65.

JHA, S. K., KRISHNAN, R. T. (2013), Local Innovation: The Key to Globalization, IIMB Management Review, 25, 249-256.

KAHLE, H. N., DUBIEL, A., ERNST, H. (2013), The Democratizing Effects of Frugal Innovation, Journal of Indian Business Research, 5(4), 230-234.

KRISHNAN, R. T. (2010), From Jugaad to Systematic Innovation: The Challenge for India, The Utpreraka Foundation.

LASTOVICKA, J., BETTENCOURT, L., HIGHNER, R., KUNTZE, R. (1999), Lifestyle of the Tight and Frugal, Journal of Consumer Research, 26, 85-98.

LEADBEATER, C. (2014), The Frugal Innovator: Creating Change on a Shoestring Budget, London, Palgrave Macmillan.

LE BOURHIS, F., KERBRAT, O., DEMBINSKY, L., HASCOET, J.Y., MOGNOL, P. (2014), Predictive Model for Environmental Assessment in Additive Manufacturing Process, Procedia CIRP, 15, 26-31.

LECOMTE, C., BLANCO, E., TROMPETTE, P., CHOLEZ, C. (2013), Towards a better Frugal Design Using Persona: Issues and Insights from an Ethnography on Prosthetics in Vietnam, 3I Conference paper, Accessed online in 2015. URL: http://www.i-3.fr/wp-content/uploads/2013/04/Lecomte_conferenceI32013.pdf

LEWIS, J. (2015), Barriers to Women's Involvement in Hackerspaces and Makerspaces, Accessed online in February 2016. http://access-space.org/wp-content/uploads/2015/10/ Barriers-to-womens-involvement-in-hackspaces-and-makerspaces.pdf

LONDON, T., HART, S. (2010), Next Generation Business Strategies for the Base of the Pyramid, Pearson Education, Inc., FT Press, Upper Saddle River, NJ.

MAIR, J., MARTI, I., VENTRESCA, M. J. (2012), Building Inclusive Markets in Rural Bangladesh: How Intermediaries Work Institutional Voids, Academy of Management Journal, 55, 819-850.

MAVRI, M. (2015), Redesigning a Production Chain Based on 3D printing Technology, Knowledge and Process Management, 22(3), 141-147.

McGEE, J., SAMMUT-BONNICI, T. (2014), Frugal Innovation, in Wiley Encyclopaedia of Management, C. L. Cooper (ed.), London, John Wiley \&Sons.

McKINSEY and COMPANY (2014), 3-D Printing Takes Shape, Accessed online in 2016. URL: http://www.mckinsey.com/insights/manufacturing/3-d_printing_takes_shape

MENICHINELLI, M. (2011), Business Models for FabLabs, Accessed online in 2016. URL:http://www.openp2pdesign.org/2011/fabbing/business-models-for-fab-labs/

METAL POWDER REPORT (2014a), 3D Printing the World's First Metal Bicycle Frame, 69(2), 38-40.

METAL POWDER REPORT (2014b), 3D Printing Market to Grow 23\% Annually, 69(1), 42.

MOSKVITCH, K. (2011), Artificial Blood Vessels Created on a 3D Printer, Accessed online in 2016. URL: http://www.bbc.com/news/technology-14946808.

NUMERAMA (2015), Une imprimante 3D qui utilise jusqu'à 10 matériaux pour un même objet, Accessed online in 2015. URL: http://www.numerama.com/magazine/34045une-imprimante-3d-qui-utilise-jusqu-a-10-materiaux-pour-un-meme-objet. html\#LhrAHrWJRQqcp8CC.99 
PETrovic, V., GONZAlEZ, J. V. H., FERrAndo, O. J., GORdillo, J. D., PUCHADES, J. R. B., GRINAN, L. P. (2011), Additive Layered Manufacturing: Sectors of Industrial Application Shown through Case Studies, International Journal of Product Research, 49, 1061-1079.

PRAHALAD, C. K. (2004), The Fortune of the Bottom of the Pyramid, Upper Sadler River, NJ, Wharton School Publishing.

PRAHALAD, C. K., MASHELKAR, R. A. (2010), Innovation's Holy Grail, Harvard Business Review, 88(7-8), 132-141.

PRAHALAD, C. K., RAMASWAMY, V. (2004), Co-Creation Experiences: The Next Practice in Value Creation, Journal of Interactive Marketing, 18(3), 12-18.

PRAHALAD, C. K. (2012), Bottom of the Pyramid as a Source of Breakthrough Innovations, Journal of Product Innovation Management, 29(1), 6-12.

RADJOU, N., PRAHBU, J. (2013), Frugal Innovation: A New Business Paradigm, INSEAD Articles. URL: http://knowledge.insead.edu/innovation/frugal-innovation-anew-business-paradigm-2375

RADJOU, N., PRABHU, J., AHUJA, S. (2012), Jugaad Innovation: Think Frugal, Be Flexible, Generate Breakthrough Growth, San Francisco, Jossey-Bass, Accessed online in 2015. URL: www.jugaadinnovation.com

RANGAN, V. K., QUELCH, J. A., HERRERO, G., BARTON, B. (2007), Business Solutions for the Global Poor: Creating Social and Economic Value, in V. K. Rangan, J. A. Quelch, G. Herrero, B. Barton (eds), John Wiley, San Francisco, Jossey Bass.

RANGASWAMY, N., DENSMORE, M. (2013), Understanding Jugaad: ICTD and the Tensions of Appropriation, Innovation and Utility, Paper presented at the Proceedings of the Sixth International Conference on Information and Communications Technologies and Development.

RANKIN, T. M., GIOVINCO, N. A., CUCHER, D. J., WATTS, G., HURWITZ, B., ARMSTRON, D. G. (2014), Three-Dimensional Printing Surgical Instruments: Are We There Yet?, Journal of Surgical Research, 189, 193-197.

RAY, P. K., RAY, S. (2010), Resource-Constrained Innovation for Emerging Economies: The Case of the Indian Telecommunications Industry, IEEE Transactions on Engineering Management, 57(1), 144-156.

RAYNA, T., STRIUKOVA, L. (2016), From Rapid Prototyping to Home Fabrication: How 3D Printing is Changing Business Model Innovation, Technological Forecasting $\mathcal{E}$ Social Change, 102, 214-224.

REDLICH, T., KRENZ, P., BASMER, S. V., BUXBAUM-CONRADI, S., WULF, S., WULFSBERG, J. P. (2014), The Impact of Openness on Value Co-creation in Production Networks, Procedia CIRP, 16, 44-49.

REICHENTAL, A. (2014), What's Next in 3D Printing?, TED talks, Vancouver, Canada, Accessed online in 2016. URL: http://www.ted.com/talks/avi_reichental_what_s_next_ in_3d_printing/transcript.

REPRAP COMMUNITY (2015), RepRap, Accessed online in 2015. URL: http://reprap.org/ ROLAND BERGER STRATEGY CONSULTANTS (2015), Think Act Frugal Products, Accessed online in 2016. URL: http://www.rolandberger.be/media/pdf/Roland_Berger_ TAB_Frugal_Products_Belgium_20150608.pdf. 
SEGHAL, V, DEHOFF, K, PANNEER, G. (2011), Frugal Engineering-Back to Basics, Market Leader Quarter, 1, 33-37.

SHARMA, A., IYER, G. R. (2012), Resource-Constrained Product Development: Implications for Green Marketing and Green Supply Chains, Industrial Marketing Management, 41, 599-608.

SIMULA, H., HOSSAIN, M., HALME, M. (2015), Frugal and Reverse Innovation: Quo Vadis?, Current science, 109(9), 1567-1572.

SONI, P., KRISHNAN, R. T. (2014), Frugal Innovation: Aligning Theory, Practice and Public Policy, Journal of Indian Research Business 6(1), 29-47.

THE ECONOMIST (2012), A Third Industrial Revolution, Special Report: Manufacturing and Innovation, Accessed online in 2016. URL: http://www.economist.com/node/21552901 TROXLER, P. (2010), Commons-Based Peer Production of Physical Goods: Is There Room for a Hybrid Innovation Ecology?, 3rd Free Culture Research Conference in Berlin, Accessed online in February 2016. http://www.openp2pdesign.org/2011/fabbing/business-modelsfor-fab-labs/

WILLIAMSON, P. (2010), Cost Innovation: Preparing for a Value-For-Money Revolution, Long Range Planning, 43, 343-353.

WOHLER'S REPORT (2014), 3D Printing and Additive Manufacturing Industry Expected to Quadruple in Size in Four Years, Accessed online in 2016. URL: http://wohlersassociates.com/press65.html

ZESCHKY, M., WIDENMAYER, B., GASSMANN, O. (2011), Frugal Innovation in Emerging Markets: The Case of Mettler Toledo, Research Technology Management, 54(4), $38-45$.

ZESCHKY, M., WIDENMAYER, B., GASSMAN, O. (2014), Organising for Reverse Innovation in Western MNCs: The Role of Frugal Product Innovation Capabilities, International Journal of Technology Management, 64(2), 255-275. 